\title{
Trauma Severity at Level 2 Trauma Center - Attainability of Retrospective Documentation on Severity
}

\author{
Hebsgaard $\mathbf{S}^{1 *}$, Zwisler $\mathbf{S}^{1}$ and Lauritsen $\mathrm{J}^{\mathbf{2}}$ \\ ${ }^{1}$ Odense University Hospital, Svendborg Hospital, Department of Anesthesiology and Intensive Care, Svendborg, Denmark \\ ${ }^{2}$ Odense University Hospital, Department of Orthopedics, Accident Analysis Group, Odense, Denmark
}

Received: November 02, 2014; Accepted: March 02, 2015, Published: March 20, 2015

*Corresponding author: Stine Hebsgaard, Odense University Hospital, Svendborg Hospital, Department of Anesthesiology, Valdemarsgade 53, DK 5700, Svendborg, Denmark, Tel: + 452-681-4697; E-mail: stine.hebsgaard@gmail.com

\begin{abstract}
Background: Centralizing and specializing in Danish health care is ongoing. Around the country Mobile Emergency Care Units (MECU) are introduced during the past years. Pre-hospital triage is important to evaluate at which trauma level the severely injured patients must be received. The aim of our study was to evaluate changes in the severity in adult traffic related high injury traumas admitted to a level 2 trauma center at Odense University Hospital, Svendborg Hospital (OUH-SH) during the last decade and before and after the introduction of the local MECU through the years 2007-2009.

Methods: The study was a retrospective study covering an eleven-year period from 2002-2012. All admissions from traffic accidents to $\mathrm{OUH}, \mathrm{SH}$ were extracted from the hospital inpatient registry for patients aged $18+$. The study was performed as a pilot study including only patients born $1^{\text {st }} 6^{\text {th }}$ in every month. Based on clinical record reviews and radiology findings, we decided if the patient was Multi Trauma (MT) defined as received by trauma response team and/or CT trauma scanned. Diagnoses were evaluated and maximum Abbreviated Injury Score (mAIS) was assigned dividing patients in severe injured with $\mathrm{mAIS} \geq 3$ and less injured with mAIS < 3. Data was compared as proportions and confidence intervals and furthermore data before and after the launching of the MECU was dichotomized.
\end{abstract}

Results: A total of 363 traffic injury patients were identified. Five were undeterminable in MT status and 137 non-MT patients were excluded, giving 221 adult MT cases for analysis. Forty-one patients (19\%, CI: 14-24) had mAIS $\geq 3$. Percentages varied with year from $0-29 \%$ with no up- or downwards trend throughout the decade. Proportion of mAIS $\geq 3$ in the years before implementing the MECU in Svendborg was $17.1 \%$ (CI: 10.2-24.0) versus $23.9 \%$ (CI: 11.1-36.7) in the years after the implementation $(p=0.32)$. The admission rate on MT's dropped from 24 to 15 and for mAIS $\geq 3$ from 4 to 3.5 .

Conclusions: There was no significant change in the proportion of severely injured patients admitted to this level 2 trauma center during the last decade or after implementation of the local MECU in this study. However, a reduction in admission rate for MT's might suggest a reduction in overtriage.

Keywords: Multi trauma; Severity of trauma; Level trauma center; Medical emergency care unit; Prehospital emergency care

\section{Introduction}

In Denmark, we have a free health-care system for the entire population financed by taxes. Centralizing and specializing in health-care is evolving [1], which among others is shown as an ongoing reconstruction of the health-care system. So-called Super Hospitals are under construction around the biggest cities to embrace the needs of modern highly specialized treatment. Some more peripheral placed hospitals are degrading to less acute preparedness, or upgrading to solitary elective or acute functions and others are even closing. The pre-hospital care and treatment is upgrading, for instance by the introduction of the Mobile Emergency Care Units (MECU) across the country during the last decade. The MECU consists of a rapid-response car, manned with a specialist in Anesthesiology and an Emergency Medical Technician (EMT). In this setting, the MECU was introduced part time in 2007 and $24 / 7$ on $1^{\text {st }}$ of September in 2009. However, needing the correct triage and admission at a suitable level of health care, the thought is that pre-hospital triage is essential for the patient outcome [2-5]. Strictly pre-hospital trauma triage by specific criteria is found to have high sensitivity but have an overtriage up to $90 \%$ [6,7], if the influence of a paramedic is added, the over-triage is found to fall to $25-50 \%$ [7]. However, a single Danish study could not show a significant fall in over-triage after the introduction of the MECU [6].

There is a great amount of trauma scoring systems. One is the Abbreviated Injury Scale (AIS) which is an anatomical-based coding system created by the Association for the Advancement of Automotive Medicine to classify and describe the severity of specific individual injuries [8]. For evaluating the severity of an injury, the score $1-6$ is used: $1=$ minor, $2=$ moderate $3=$ serious, 4 $=$ severe $5=$ critical $6=$ lethal $[8,9]$. Maximum Abbreviated Injury Scale (mAIS) score is the highest region-based injury score, and used for trauma severity assessment. MAIS $\geq 3$ is generally seen as the set point for serious trauma [9], as the value three of mAIS has risk of death at $10 \%$. MAIS has been evaluated to have similar abilities with other scoring systems in discriminating between survivors and non-survivors, but found better than the Injury Severity Score (ISS) [10]. 
The aim of the study was to 1: Establish a complete sample of traffic-related injury patients received as multi trauma (MT) at Odense University Hospital, Svendborg Hospital (OUH-SH) from 2002-2012. 2: Evaluate the severity of based on mAIS. 3: Evaluate a hypothesized change in the number and severity of the MT's after the introduction of the MECU through the years 2007-2009.

\section{Methods}

\section{Setting}

The study was conducted in Denmark, a country with a population of 5,600,000 [11]. The study took place at Odense University Hospital, Svendborg Hospital a peripheral hospital with a level 2 trauma center placed at the southern part of Funen. The hospital is an independent part of Odense University Hospital; the unit covers the entire Funen and has about 1200 beds [12]. Funen is an island which population is corresponding to about a tenth of the entire Danish population.

The study was approved by the Danish Data Protection Board, (Journal number: 2008-58-0035, 14/4601). According to Danish law, approval from an ethics committee is not required for register studies.

The study was a retrospective database study covering an eleven-year period from 01.01.2002-31.12.2012. We sought all records regarding traffic related injury with following acute admission to OUH-SH and grouped them MT or not MT. MT was defined as received by the trauma response team and/or a performed trauma CT-scan. We compared them to all records of multi trauma patients with the Danish Diagnostic Code of MT: dT079 "multiple injuries without specification".

The study was carried out as a pilot study, and evaluated a subsample of patients born on a $1^{\text {st }}$ to $6^{\text {th }}$ during the study period. This selection eliminates the risk of bias on selection.

Inclusion criteria

- MT received at OUH-SH in the defined period.

Exclusion criteria

- Age at trauma $<18$ years.

- MT dead at arrival at the hospital.

- MT of other reasons than traffic.

- Impossible to determine MT status.

We investigated medical journals in the relevant patient journal programs and radiology examinations, and decided if the patient was MT or not. If the patient was MT, we continued to evaluate the diagnoses and assigned an abbreviated injury scale value for the most severe injury registered (AIS 2005), because the AIS was not automatically assigned by the receiving department. If there was any doubt about the assigned mAIS, the records would thoroughly be re-investigated until agreement of a mAIS between coauthors. We divided the MTs into two groups: Severely injured or less injured. Severely injured was defined as $\mathrm{mAIS} \geq 3$ or death within 24 hours after admission, as it was assumed that the patient had scored mAIS $\geq 3$ if he had survived long enough to carry out complete diagnostics $[13,14]$.

We furthermore compared mAIS before and after implementing the MECU 24/7 in Svendborg September $1^{\text {st }} 2009$. We excluded data from 2007, 2008 and 2009 since the MECU was launching part time from 2007.

\section{Statistical analysis}

All statistical analyses were done using STATA 10 (www. stata.com). Figure 2 and 3 with EpiData Analysis (www.epidata. $\mathrm{dk}$ ). Descriptive results are presented as actual counts and proportions (stata procedure ci) among all within a given group. Due to low level of missing data no particular efforts were made to analyze possible biases in relation to this.

Heterogeneity for mAIS $\geq 3$ before and after launching the MECU was compared using chi $^{2}$ including odds-ratio and Confidence Intervals (CI). Statistical significance was for all tests set at the $p<0.05$ level. Attempts to analyze trend in proportions showed non-significant results and due to the low overall number of observations in this pilot study, it was not pursued any further.

\section{Results}

We registered 423 traffic related acute admissions of patients

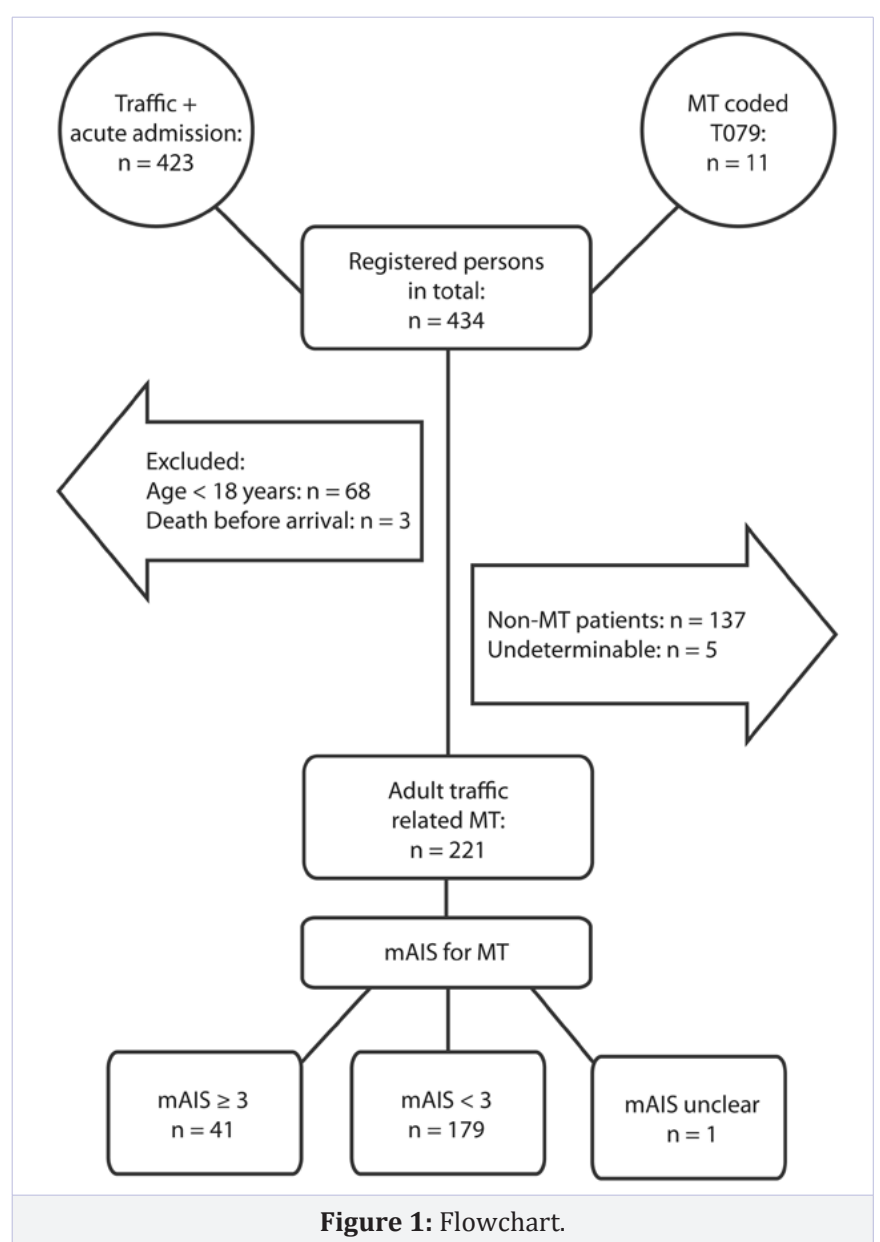


(Figure 1). Based on the diagnostic code T079 we found additional 11 traffic related MTs, giving 434 individuals born on the $1^{\text {st }}-6^{\text {th }}$ in every month with a visit from 01.01.2002-31.12.2012. We excluded patients who died before arrival to trauma center $(\mathrm{n}=$ 3 ) and patients aged $<18$ years at the time of trauma $(n=68)$. We removed admissions of other reasons than MT $(n=137)$ and cases $(n \geq 5)$ where it was undeterminable if the case was trauma or not, giving 221 adult traffic related MT for analysis.

It was possible to decide mAIS in 220 cases. Forty-one of those were severely injured (mAIS $\geq 3$ ) and 179 were not. There was no significant decrease or increase in number of MT during the evaluated decade (Table 1 ). The share of mAIS $\geq 3$ varied with year from $0.0-29.4 \%$ with no up or downwards trend throughout the decade (CI: 14.0-24.2). The proportions including CI are shown in Figure 2.

We divided the MT's into two groups pre $(\mathrm{n}=118)$ and post ( $\mathrm{n}=46$ ) the implementation of the MECU. Excluding the MT received in the period from 2007-2009 where the MECU was introduced part-time $(\mathrm{n}=57)$. In the pre-MECU group 20 patients scored $\mathrm{mAIS} \geq 3$ and $97 \mathrm{mAIS}<3$ and in the post-MECU group, 11 scored $\mathrm{mAIS} \geq 3$ and $35 \mathrm{mAIS}<3$ (Table 2 ).

The groups were compared with $\mathrm{chi}^{2}$-test, and the mean proportions of mAIS $\geq 3$ in the pre-MECU-group was 17.1 (CI: $10.2-24.0$ ) versus $23.9 \%$ (CI: 11.1-36.7) in the post-MECU-group, odds ratio 0.65 (CI: 0.27-1.68), $(p=0.32)$ (Figure 3).

\section{Discussion}

The study has shown that we could establish a cohort of traffic related injury patients received as MT. When evaluating the development in the severity (based on mAIS) of traffic related adult MT brought primarily to a level 2 trauma center, we found no significant difference throughout the last decade. In addition, we were not able to find an impact in the severity of the traumas before and after implementing the MECU. However, the admission rate dropped from 24 (pre-MECU) to 15 (post-MECU) per year, while the admission rate for $\mathrm{mAIS} \geq 3$ seemed stable at 4 versus 3.5. With caution, this could suggest a decrease in prehospital over-triage.

Table 1: Number of traffic related Multi Trauma 2002-2012 according to Maximum Abbreviated Injury Score (mAIS).

\begin{tabular}{|c|c|c|c|}
\hline Year & $\mathbf{m A I S}<3$ & $\mathrm{mAIS} \geq 3$ & Number of Trauma \\
\hline 2002 & 14 & 2 & $17^{\mathrm{a}}$ \\
\hline 2003 & 23 & 8 & 31 \\
\hline 2005 & 22 & 2 & 24 \\
\hline 2006 & 24 & 4 & 28 \\
\hline 2007 & 16 & 5 & 21 \\
\hline 2008 & 17 & 5 & 22 \\
\hline 2009 & 14 & 0 & 14 \\
\hline 2010 & 9 & 3 & 12 \\
\hline 2011 & 14 & 3 & 17 \\
\hline 2012 & 12 & 5 & 17 \\
\hline Overall 2002-2012 & 179 & 41 & 221 \\
\hline
\end{tabular}

a: Data missing for 1 patient

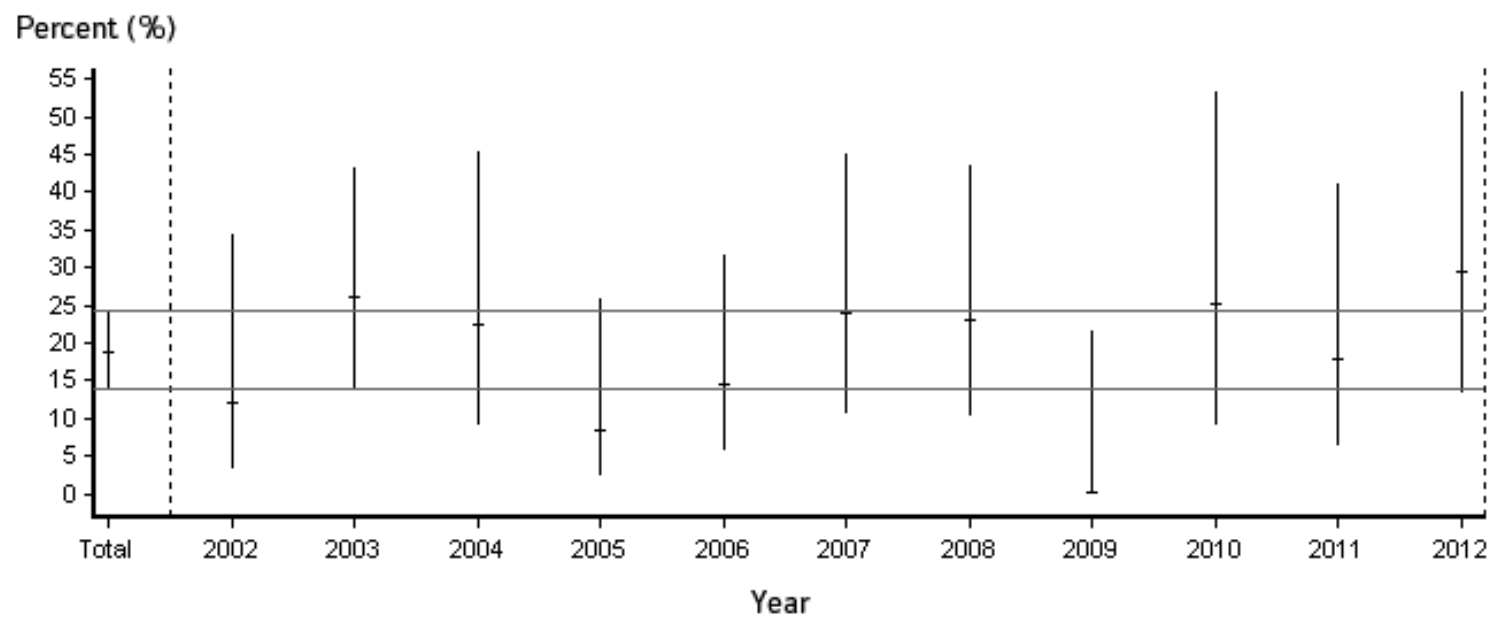

Figure 2: Proportion of Maximum Abbreviated Injury Score (mAIS) $\geq 3$ for each year 2002-2012 including confidence intervals. 
As result of improved pre-hospital triage and care as well as a rising trend of specializing and centralizing in health care ${ }^{1}$, we expected a reduction in incidence of severe injured admitted to this level 2 trauma center, as we had expected the most seriously injured to be transferred directly to the level 1 trauma center only $45 \mathrm{~km}$ away. In addition, we had expected the pre-hospital triage by an anesthesiologist would decrease the total number of MT at this level 2 trauma center, as well as a reduction in overtriage in trauma $[3,4,6]$.

If the pre-hospital treatment is strengthened for instance by more paramedics or MECU's the pre-hospital triage is expected to improve and the most severe injured will more likely be admitted to a level 1 trauma center even though the distance might be longer $[2,3,14]$. Though, less severe injured could be expected to be received at a level 2 trauma center as $\mathrm{OUH}-\mathrm{SH}$, as well as the number of trauma in general might be reduced.

In spite of an ongoing upgrading of the pre-hospital triage including the MECU in Southern Funen, we did not find a change in the number of MT received at OUH-SH from 2002-2012. In addition, we could not show a significant change in severity over the same period. In Denmark, specializing of physicians are undertaken part time at a peripheral hospital and part time at a university hospital. It could be suspected that a decreasing number of MT or a decrease in severity of MT could influence the experience of the local trauma response team and reduce the possibility to educate physicians, which could lead to an increase in mortality [15] .

We did not find the implementation of the MECU affective on the grade of severity at our level 2 trauma center $(p=0.32)$. However, we are aware of the different size of the pre- and postgroup, but in the current setting it was not possible to extend the post-period, as a result the CI is wider (Figure 3).

Our findings could be associated with more accurate triage by the pre-hospital anesthesiologist, reducing the rate of nonsevere MT admissions (less overtriage), but an unchanged rate of severe injured triaged suitable for our level 2 trauma center [2] including traumas with no apparent need for thoracic or cerebral surgical intervention. Our goal was not to evaluate undertriage, therefore secondary transfer to the nearby level 1 trauma center pre- and post-implementation of the MECU was not evaluated in this setting. In addition to our study, a formerly Danish study from another level 2 trauma center could not show a change in overtriage or undertriage after implementation of the MECU [6].

Table 2: Comparison of traffic related trauma before and after launching of Mobile Emergency Care Unit (MECU) according to Maximum Abbreviated Injury Score (mAIS).

\begin{tabular}{|c|c|c|c|c|}
\hline & $\begin{array}{c}\text { mAIS < } \\
3(\%)\end{array}$ & $\begin{array}{l}\text { mAIS } \geq \\
3(\%)\end{array}$ & $\begin{array}{l}\mathrm{mAIS} \geq 3 \\
\quad\left(\mathrm{CI}^{\mathrm{a}}\right)\end{array}$ & $\begin{array}{c}\text { Odds ratio } \mathrm{mAIS} \geq 3 \text { before } \\
\text { vs. after } \mathrm{MECU}\left(\mathrm{CI}^{\mathrm{a}}\right)\end{array}$ \\
\hline $\begin{array}{l}\text { Before } \\
\text { MECU }\end{array}$ & $\begin{array}{c}97 \\
(82.9)\end{array}$ & $\begin{array}{c}20 \\
(17.1)\end{array}$ & $(0.10-0.24)$ & $0.65^{b}$ \\
\hline $\begin{array}{l}\text { After } \\
\text { MECU }\end{array}$ & $\begin{array}{c}35 \\
(76.1)\end{array}$ & $\begin{array}{c}11 \\
(23.9)\end{array}$ & $(0.11-0.37)$ & $(0.26-1.68)$ \\
\hline
\end{tabular}

a: Confidence Interval; b: $p=0.32$

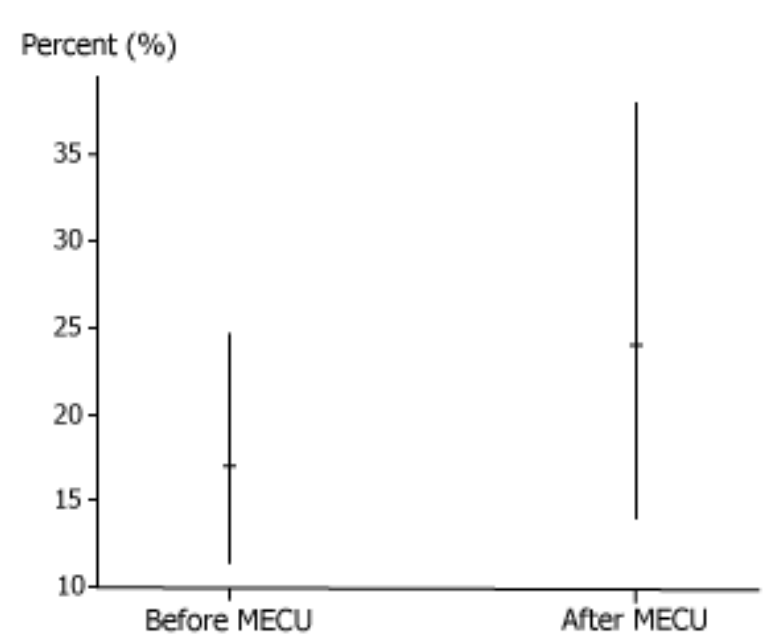

Figure 3: Proportion of Maximum Abbreviated Injury Score (mAIS) $\geq 3$ before and after launching of the Mobile Emergency Care Unit (MECU) including confidence intervals.

Undertriage is known to be associated with increased mortality of more than $25 \%$ if admitted to a non-trauma center [13], and in addition to that mortality is found to increase up to $30 \%$ for severely injured MT admitted to a non-trauma center compared to a trauma center [14]. Otherwise the grade of undertriage in Denmark is found very low (0.4-1, 1\%) [6]. Another Danish study shows that the deployment of the MECU reduced undertriage and secondary transfer to a trauma center [3].

A retrospective study has several limitations. There is a risk of incomplete data collection (a retrospective bias). Our data is based on the coding for acute admission and traffic, as it early in the process was clear that - especially in the early years of the investigated period, the trauma code dT079 was recorded insufficiently. This is the reason why other reasons for trauma than traffic were not included, simply because of the difficulties of confirming data. However, traffic related MT is shown to be the major cause of trauma $[2,6]$. Further research could benefit from a prospective view or a systematic review, though more research in this area is needed.

The study is a pilot study hence the data is selected. We sought to analyze a representative amount of data by evaluating the patients born on a $1^{\text {st }}$ to $6^{\text {th }}$ during the study period. This way we sought to eliminate date based selection with season-related trauma. We found it unlikely that inclusion of all approximately 2000-3000 patients during the study period would change the results, although the statistic power to discriminate differences would be enhanced.

During the study period a new highway was build connecting the area even more easily to the level 1 trauma center. We did not stratify for this, even if this could have meant an even larger risk of the severity decreasing at the level 2 trauma centers.

In conclusion, we did not find a trend of decreasing or 
increasing severity of the traffic related traumas brought to the level 2 trauma center OUH-SH through the last decade. The implementation of a local MECU did not seem to affect the share of severity significantly, though the admission rate dropped after the implementation suggesting reduction in overtriage, however, further research in this area is needed.

\section{References}

1. Danish Regions. Sammenhæng i sundhedsvæsnet. [Cited 2011-08-24] Available from: http://www.regioner.dk/ /media/Filer/Sundhed/ Sammenh\%C3\%A6ng i sundhedsv\%C3\%A6senet_2011.ashx

2. Cameron PA, Gabbe BJ, Smith K, Mitra B. Triaging the right patient to the right place in the shortest time. Br J Anaesth. 2014; 113(2): 22633. doi:10.1093/bja/aeu231

3. Meisler R, Berlac PA. Prehospital trauma triage before and after deployment of a physician-manned mobile emergency care unit in Nordsjaelland. Ugeskr Laeger. 2009; 171(36): 2548-2552.

4. Frykberg ER. Triage: Principles and Practice. Scand J Surg. 2005; 94(4): 272-278. doi:10.1177/145749690509400405

5. Svenson J. Trauma systems and timing of patient transfer: are we improving? Am J Emerg Med. 2008; 26(4): 465-468. doi:10.1016/j. ajem.2007.05.013

6. Burén LA, Daugaard M, Larsen JK, Laustrup TK. Visitation by physicians did not improve triage in trauma patients. Dan Med J. 2013; 60(11): A4717.

7. Cox S, Smith K, Currell A, Harriss L, Barger B, Cameron P. Differentiation of confirmed major trauma patients and potential major trauma patients using pre-hospital trauma triage criteria. Injury. 2011; 42(9): 889-95. doi:10.1016/j.injury.2010.03.035

8. Abbreviated Injury Scale. [Cited 2014-10-02]. Available from: http:// www.trauma.org/archive/scores/ais.html

9. Champion HR. Trauma scoring. Scand J Surg. 2002; 91(1):12-22. doi:10.1016/B978-0-323-04418-9.50010-2

10. Meredith JW, Evans G, Kilgo PD, MacKenzie E, Osler T, McGwin G, et al. A comparison of the abilities of nine scoring algorithms in predicting mortality. J Trauma. 2002; 53(4):621-628; doi:10.1097/00005373200210000-00001

11. Population in Denmark: Key Figures - Statistics Denmark. [Cited 201409-23]. Available from: http://www.dst.dk/en/Statistik/emner/ befolkning-og-befolkningsfremskrivning/folketal.aspx

12.Odense Univ Hosp webpage. [Cited 2014-10-05]. Available from: http://www.ouh.dk/wm399479

13. Haas B, Gomez D, Zagorski B, Stukel TA, Rubenfeld GD, Nathens AB. Survival of the fittest: the hidden cost of undertriage of major trauma. J Am Coll Surg. 2010; 211(6): 804-811. doi:10.1016/j. jamcollsurg.2010.08.014

14. Haas B1, Stukel TA, Gomez D, Zagorski B, De Mestral C, Sharma SV, et al. The mortality benefit of direct trauma center transport in a regional trauma system. J Trauma Acute Care Surg. 2012; 72(6): 1510 1517. doi:10.1097/TA.0b013e318252510a

15. Simon R, Stone M, Cucuzzo J. The impact of a new trauma center on an existing nearby trauma center. J Trauma. 2009; 67(3): 645-50. doi:10.1097/TA.0b013e31818cae0c 